cal recruitment campaign within our membership. At all STFM conferences this year, you will see buttons with "Future Family Docs Rocks!" emblazoned. At the Conference on Predoctoral Education in Memphis, Tenn, at the Conference on Families and Health in Austin, Tex, and at the Annual Spring Conference in Chicago, Ill, we will continue the buzz, highlighting the presentations that focus on mentoring and the pipeline and combing the conference for new programs and creative ideas to share on the Web. We will feature inspiring stories in our STFM Messenger, in Family Medicine, and in our organizational update in the Annals of Family Medicine.

STFM will link to other sister organizations such as (1) the AAFP and its new resource booklet for college and high school students called, "Explore Family Medicine...A Roadmap for Your Future," (2) the AAMC Web site (http://www.AspiringDocs.com), promoting health careers in minority college and high school students, and (3) the National AHEC Web site (http:// www.nationalahec.org), where you can discover AHEC programs that link community children to programs promoting and supporting health careers.

I'd like to recognize the STFM Strategic Task Force Subcommittee for Premedical Recruitment: Terry Steyer, MD; Charles Mouton, MDi Stacy Brungardt, $\mathrm{CAE}_{;}$and the Future Family Docs Web site coordinating group: Dede Willis, MD, MBA, (inventory); Teresa Kulie, MD (stories); Carman Whiting, MD (resources); and Terry Steyer, MD (legislative issues).

I encourage you to jump on board the Future Family Docs bandwagon and check out the Web site today!

Janice Benson, MD

STFM FFM Special Task Force

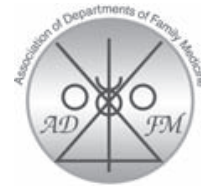

From the Association

of Departments of Family Medicine

Ann Fam Med 2007;5:183-184. DOI: 10.1370/afm.688.

\section{THE AAMC ACADEMIC CHRONIC CARE COLLABORATIVE: FAMILY MEDICINE'S PARTICIPATION AND LESSONS LEARNED}

Beginning in June 2005, a cohort of 48 teams assembled to participate in the first chronic care collaborative that enrolled teams only from the nation's teaching hospitals. The Academic Chronic Care Collaborative (ACCC), formed through a partnership between the AAMC's Institute for Improving Clinical Care and the RWJF's Improving Chronic Illness Care program had dual goals: to improve both the care of patients with chronic illness and the education of health care teams providing care in academic settings.

Specific goals of the collaborative included facilitation of evidence-based improvements, partnership with improvement-focused institutions, identification of improvement innovators practicing in academic settings, convening of these innovators and other experts to craft strategies to move the academic medical community toward better care and learning, and supporting these faculty to develop their academic careers around healthcare improvement.

Teams, representing 22 distinct academic centers, spent the next 15 months implementing changes in the care of selected chronic conditions, including diabetes, asthma, and COPD, using Wagner's Chronic Care Model. Eleven teams were from family medicine training programs, including Southern Illinois University, Lehigh Valley Hospital Network, Harbor-UCLA Medical Center, Duke University Medical Center, University of Colorado Health Sciences Center, University of Cincinnati Medical Center, University of Louisville Health Sciences Center, University of Minnesota School of Medicine, University of South Carolina School of Medicine, NEOUCOM's Summa Health System, Albert Einstein College of Medicine's Montefiore Medical Center, and University of Kentucky Medical School.

The Collaborative, led by co-chairs Dr David Stevens and Dr Ed Wagner and Director Connie Sixta, employed the Breakthrough Series Collaborative learning model developed by the Institute for Healthcare Improvement (IHI), in which multidisciplinary teams attended a kick-off session, 2 face-to-face interactive learning sessions, a virtual learning session, and a congress that coincided with the AAMC Annual Meeting. Between each learning session, teams utilized change packages that were comprised of evidence-based strategies structured around the CCM. Participating teams learned from each other and had access to expert advice.

Departments with participating ACCC teams substantially supported their teams. Participating teams were expected to perform pre-work activities; attend all learning sessions; provide a physician champion; test improvement strategies; use a patient registry to monitor and report outcomes and submit monthly progress reports. Teams were also expected to develop curriculum for learners that paralleled their work in adopting the CCM and to test the impact of these curricular changes.

Early data from the collaborative demonstrate high enthusiasm for this project, as evidenced by the large percentage of on-time monthly reports, high-level participation on monthly conference calls, high reten- 
tion rates of champion physicians, and heavy listserv activity. Mechanisms that were utilized by teams to improve clinical outcomes included development of interventions to impact clinical inertia, extensive use of provider-specific data, a major focus on enhancing self management support, a realization that work and improvement occurs best among multidisciplinary teams, and extensive use of group and planned visits. Changes in resident curriculum included changes in both didactic and hands-on clinical training.

Participating programs have already cited a variety of benefits from ACCC participation, including a rethinking of the way patient care is provided that is more consistent with the FFM Model (ie, group visits, self-management, multidisciplinary teams, community effort). Additional benefits have included a positive impact on departmental strategic planning, greater resident appreciation of team care; an inclusion of nontraditional roles, such as data analyst into the care process; greater group learning about the challenges

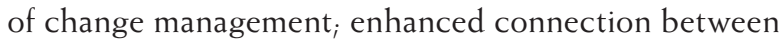
senior leaders and teams; and a positive impact on resident recruiting. Additionally, quality improvement work was recognized as rigorous research and a viable career focus. Lastly, there was a feeling that the collaborative helped advance the diffusion of innovation across departments within the same campus.

Several spinoff efforts have resulted from this initial academic collaborative. The AAMC's Institute for Improving Clinical Care (IICC), in partnership with the University of Pittsburgh Medical Center and the Delmarva Foundation for Medical Care, coordinated an Academic Rapid Response Collaborative for improving acute care in academic settings. In May 2006, 10 teams from North and South Carolina began participating in a 2-year collaborative to improve diabetes and $\mathrm{CHF}$ care in family medicine residency programs in the Carolinas. Funding from Fullerton Foundation and Duke Endowment support the design team, which includes leadership from the UNC Department of Family Medicine and USCSCOM Department of Family and Preventive Medicine. And, in February of this year, the California Academic Chronic Care Collaborative began their work to improve chronic illness care for persons who receive their care in academic health systems and to assure that clinical education occurs in an exemplary environment with teams from 8 California institutions.

Elizabeth G. Baxley, MD and Michele Stanek, MHS and the Association of Departments of Family Medicine

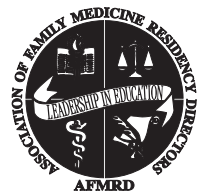

From the Association of Family Medicine Residency Directors

Ann Fam Med 2007:5:184-185. DOI: 10.1370/afm.689.

\section{MATERNITY CARE IN FAMILY MEDICINE:} A TIME FOR DIALOGUE

Maternity care is a core tenet of family medicine, and has been reaffirmed in the Future of Family Medicine report. Although there is wide regional variation in training experience, family medicine residency can prepare residents for competency in maternity care. Our nation, especially rural areas, needs family physicians who deliver babies and provide access to care. Some family medicine residency programs offer advanced skills, including management of high-risk pregnancy and operative delivery. However, many of our programs struggle with the current Residency Review Committee (RRC) requirements for maternity care. Delivery numbers (both continuity and total) vary widely across the country. Given geography, payor mix, and liability costs, some programs have no family medicine faculty to supervise residency training in maternity care. These facts produce a tension and a polarity. What is routine for some is unacceptable for others. What is routine for some is unachievable by others. The debate is not "to do" or "not to do" obstetrics; the question is "the dose."

Although current RRC requirements hold all programs accountable to the same standard, the Residency Assistance Program Criteria for Excellence supports a 3tiered level of competence. Concerns over changing the numbers requirement range from support for raising the bar of competence for those obtaining maternity privileges, to fear that family medicine is "giving up on $\mathrm{OB}^{\prime \prime}$ if all residents do not obtain a minimum number. These positions include the following options:

\section{Continue Current RRC "Numbers"}

1. Obstetrical practice is at the heart of what it means to be a family doc, and through this experience, the practicing physician builds a practice of families.

2. Maternity training is a battle that current family physicians cannot quit.

3. The time for differentiation of providing (or not providing) maternity care should be after residency graduation, based on community needs.

4. Although not all of our members actively practice maternity care, maternity care training is essential.

5. The delivery experience is an excellent opportunity to evaluate the ability/competence of our residents. 